Information Technology Journal 5 (2): 322-328, 2006

ISSN 1812-5638

(C) 2006 Asian Network for Scientific Information

\title{
Working with XML for Flexible Management of Online Course Syllabi
}

\author{
${ }^{1}$ Zeynel Cebeci, ${ }^{2}$ Fuat Budak and ${ }^{3}$ Mehmet Tekdal \\ ${ }^{1}$ Department of Informatics, ${ }^{2}$ Department of Environmental Engineering, \\ ${ }^{3}$ Department of Instructional Technology, Cukurova University, 01330, Adana, Turkey
}

\begin{abstract}
Extensible Markup Language (XML) has been one of the most dominant research concepts in information exchange during recent years. Almost in every area of information technologies XML-based applications utilized to gain the advantages associated with XML and related technologies. Also in education world, XML has provided the great advantages such as shareability, reusability, durability and interoperability in-and-between technology enhanced learning and teaching systems. Researches and implementations on the use of XML in teaching and learning have mainly been focused on the development of learning objects, content packaging and learning systems design. Although it is one possible use of $\mathrm{XML}$, limited number of research works has been done on the use of XML-based syllabi within e-learning platforms. In this study, preparing online course syllabi as XML documents is discussed and an authoring tool which has been built with XML, XSL, HTML, Javascript and MS ASP is introduced for demonstrating the flexibilities of XML-based syllabi as a sample framework.
\end{abstract}

Key words: $\mathrm{XML}$ applications, syllabus construction, online teaching tools, educational software, web-based teaching and learning

\section{INTRODUCTION}

Although there are somewhat different definitions of syllabus $^{[1]}$ a syllabus is an outline of a course, a contract, a communication and interaction tool between instructors and students. According to a definition by the Center for Teaching and Learning Services at the University of Minnesota (CTLS-UM), a syllabus is one of the most important documents created for classes, serving as an agreement between teaching staff and students. It conveys a first and lasting impression of the faculty and the course designed and it documents and shares staff's beliefs about teaching ${ }^{[2]}$. Altman and Cashin suggested that a syllabus should communicate to students what the course is about, why the course is taught, where it is going and what will be required of the students for them to complete the course with a passing grade ${ }^{[3]}$. Preparing course syllabi is one of the most highly demanded and/or compulsory tasks which must be done by the staff in academic institutions.

However its strong importance in teaching and learning, preparing and delivering the course syllabi to students by using traditional methods is a time-consuming and expensive task for staff and school administrations. Furthermore a course syllabus prepared for any course in one educational institution can not be shared in similar course taught in others due to high variations in content and approaches. Therefore there is a need for systems and solutions that make syllabi management is cheap, effective, acceptable and accessible with different online platforms. In order to reduce the costs and shorten required time, online educational systems can recently be considered as the most effective and useful tools in constructing, collecting, organizing and publishing the course syllabi. During last few years, the rapid developments in Information and Communication Technologies (ICT) infrastructure made it also possible to use ICT in teaching and learning (or e-learning) in educational domains. Due to the wide-use availability of computer networks, online systems and tools, educational institutions have been trying to administrate their course syllabi with learning content management systems and/or online Web-based course catalogues besides other e-learning medium. Even though these are often just electronic copies of traditional paper syllabi, majority of online versions of course syllabi include the hyperlinks of electronic resources located on the Web. Therefore, an online course syllabus is more useful to realize the learning-centered approach as discussed by Grunnert ${ }^{[4]}$ in comparison with a traditional syllabus. In addition, an online course syllabus adds interactivity providing a dynamic dimension beyond the scope of a printed syllabus ${ }^{[s]}$.

Although many kinds of syllabus formats are available in personal and institutional online environments there are considerably high variations in the

Corresponding Author: Zeynel Cebeci, Department of Informatics, Cukurova University, 01330, Adana, Turkey 
structure of online syllabi. From the search results obtained from the Google search engine, the Syllabus Finder of the Center for History and New Media at George Mason University ${ }^{\left[{ }^{[6]}\right.}$ and Syllabus Project of the American Academy of Religion ${ }^{[]]}$it was determined that the variations do exist among syllabi for the courses which have same/similar titles and/or content in different universities. Moreover, there are also variations in structure and content of syllabi for the courses given by different faculties in the same department of a university. For instance, a search session on Google for the courses, entitled environmental protection resulted in a dissimilarity with a variation of $90 \%$ in the appearance, structural organization and content of the syllabi ${ }^{[8]}$. These findings show that standardization works should also be taken into consideration by the institutions (e.g. IEEE LTSC, IMS and ADL) which work on the standards and/or specifications for teaching and learning.

Another issue or difficulty that is decelerating the wide use of online syllabi by the teaching community is the inadequacy in number and functionalities of the tools or software that can be utilized in online environments. In order to build and publish course syllabi with online systems, although many formats from simple text files to PDF and HTML files can be applied in online environments, the specialized tools in management for authoring, editing and delivering syllabi will be preferred in this field. Indeed, it can be said that the efforts to develop and distribute these kinds of specialized syllabus tools as stand-alone applications, or integral parts of learning environments will influence the use of the online syllabi much more than we previously thought.

Even though some commercial software vendors like WebCT and Blackboard included syllabus components into their systems during the last years, these components are still rarely the built-in parts of many learning management systems (LMS) and/or learning content management systems (LCMS), especially in open source ones. On the other side of developmental projects, some computing departments at universities enlist some tools to create and publish the syllabi to the academic staff. Among them, the University of Utah's Online Services ${ }^{[9]}$ and Feather River College's syllabus maker templates ${ }^{[10]}$ are freely available on the Web. Syllabus tool, developed in the University of Arizona is one of the leading and most efficient syllabus tools ${ }^{[11]}$. The Syllabus maker in the StudentHub, a service of Santa Barbara City College can be considered a highly detailed syllabus builder tool which is accessible by the teaching community on the Web. The aim of this service was reported as completing class-specific assignments or working independently to do online research, plan large or small class projects, or access learning resources that help build independent learning skills and increase understanding of course content ${ }^{[12]}$. Buuck et al ${ }^{[13]}$ have created a standard syllabus that can serve as a model for all online syllabi because of the demand for online syllabi and the confusion over what style of syllabi would be best for the average student at Hanover College, US.

Excluding the conventional ways of creating a syllabus by the use of common document processors like MS Word and PDF Writer, the following problems were determined with the syllabus editing tools that are publicly available. Course syllabi managed with the majority of these tools are:

- Mainly in HTML format,

- Unstructured and limited in number of descriptive elements,

- Not suitable to extent the elements for different organizational situations,

- Not sharable between systems and institutions,

- Not reusable for different purposes.

Due to the problems listed above, there is an urgent need for online tools and/or systems to create course syllabi which will be used widely by teaching staff. Developing builder tools that can produce the syllabus documents in XML could serve as a solution to overcome the problems listed above.

As generally known, XML is a subset of Standard Generalised Markup Language (SGML). Its goal is to enable generic SGML to be served, received and processed on the Web in the way that is now possible with HyperText Markup Language (HTML). XML has been designed for ease of implementation and for interoperability with both SGML and HTML. XML was developed by an XML Working Group formed under the auspices of the World Wide Web Consortium (W3C) in $1996^{[14]}$. XML is a markup language for the documents containing structured information. XML specifies neither semantics nor a tag set. In fact XML is really a meta-language for describing markup languages. In other words, XML provides a facility to define tags and the structural relationships between them. Since there's no predefined tag set, there can't be any preconceived semantics. All of the semantics of an XML document will either be defined by the applications that process them or by stylesheets ${ }^{[15]}$. As a result of these characteristics of $\mathrm{XML}$, it offers many advantages for designing and delivering the course syllabi. Since the syllabus created in XML files can be used as interoperable documents, they can be transferred between different operating platforms and LMS/LCMSs without any additional conversion 
effort. Moreover, the desired parts of XML formatted syllabus documents can be processed for various purposes and displayed in different user-defined styles repeatedly.

In education, since XML is being increasingly used to describe student data (personal and achievement oriented) and also to represent reusable chunks of learning material, the use of XML has not been sufficient, by itself, to entirely define the data interface between systems $^{[16]}$. Due to the need for technical realizations of $\mathrm{XML}$ in education, developing an open source syllabus tool which will enable editing course syllabi in XML can provide great advancements. In this study, the advantages and expectations of structuring course syllabi in XML are discussed and the components and working model of SyllabuserXML, a syllabus editing tool is described in some aspects.

\section{ORGANIZATION OF SYLLABUS CONTENT (STRUCTURE OF SYLLABUS XML FILE)}

Although many different structures and content of a good syllabus were proposed and discussed by some researchers and institutions, Altman and Cashin's study ${ }^{[3]}$ has been referenced as a starting guide with online systems in many colleges and universities. The authors discuss the parts of a syllabus under the titles of course information, instructor information, course description/objectives, texts, readings, materials, course calendar/schedule, course policies and others. This segmenting is highly acceptable and covers almost all of the details which should be presented in a course syllabus. Therefore, the items suggested by Altman and Cashin $^{[3]}$ and the checklist given by Enerson et al. ${ }^{\left[{ }^{[1]}\right.}$ were used as principal sources for building the XML-based syllabus documents in this study.

A syllabus document in XML format contains all the information divided into several categories tagged with the elements and their attributes (Table 1). The first category is the basic information which must be listed for every kind of course in the curriculum of an educational program. Basic information covers the names of the institutional units in which the course is taught. The institutional units can be entered in a varying number in an order from sub units to super units (in the order of division, department, faculty, university). Each unit element in XML file has the id and url attributes in order to show the order and Web URL of the units, respectively. Information for the course number, course title, credits, semester, year, course type, course description is also included under the basic information element. Here, course type shows whether the course is an elective or compulsory course while the description identifies the content and aim of the course in general. Prerequisites express the conditional status of the course or the pre-studies that should be done before attending the course. Prerequisites can be repeated with id attributes as required as. The sections area of basic information is used to describe the location, days of the week and hours of the course when the students will attend (Table 1).

Information about the instructors presents all the necessary information for teachers, teaching and laboratory assistants. Instructor elements can be in any number in a syllabus document. Information for each instructor primarily consists of name and title elements. The role element of instructor is to explain the task of the staff like, instructor, teacher, lab assistant, teaching assistant etc. This element, used for the first time in this study, expands the number of roles and offers an important flexibility to syllabus documents (Table 1).

An ideal syllabus should list the objectives or goals of the courses in detail. The third part of syllabus documents, objectives_info element is used to list the objectives. This element encapsulates the varying number of objective elements with an id attribute which shows the order (Table 1).

Materials_info elements of XML file lists the required, recommended and reading materials such as textbooks, CDS, maps, videos, cassette, drawings etc. The materials section of the syllabus in this study was organized in two main sections as offline and online. While offline elements are the books, magazines, CDS and software which can be followed outside of an networking environment; online elements are web pages, ftp sites and software which should be followed in networking environments, often on the Internet (Table 1).

Both offline and online elements consist of different numbers of resource elements which can be repeated as many times as required. Each resource element has id, type, lang and reference (ref) attributes. Id is used to determine the order of resource; type shows the requirement status of the resources such as required, recommended reading etc. Lang attribute is for the language in which the resource is written, and ref is for the unique code of the resource in ISSN, ISBN etc. (Table 1). Resource elements are the title, authors, publishers and publishing years. The same structure is valid for online elements excluding resource attributes. In online the resource definition ref attribute is replaced with url attribute which show the network address of the resource (Table 1).

Calendar information provides the detailed list of activities for the course and covers in varying numbers of 
Inform. Technol. J., 5 (2):322-328, 2006

Table 1: Hierarchical structure and elements of a syllabus XML file

\begin{tabular}{|c|c|c|}
\hline Basic information & Instructor information & Objectives information \\
\hline 1 basic_info & 2 instructor_info & 3 objectives_info \\
\hline 1.1 institution & 2.1 instructor (id, code) * & 3.1 objective (id) * \\
\hline 1.1.1 unit (id, url) * & 2.1.1 name & \\
\hline 1.2 course & 2.1.2 title & \\
\hline 1.2.1 number & 2.1 .3 role & \\
\hline 1.2 .2 title & 2.1.4 email (id)* & \\
\hline 1.2 .3 credit & 2.1 .5 url (id)* & \\
\hline 1.2.4 semester & 2.1.6 phone (id, type) * & \\
\hline 1.2 .5 year & 2.1.6.1 area & \\
\hline 1.2.6 type & 2.1.6.2 number & \\
\hline 1.2.7 language & 2.1.6.3 restrictions & \\
\hline 1.2.8 description & 2.1.7 fax (id, type) * & \\
\hline 1.2 .9 department & 2.1.7.1 area & \\
\hline 1.3. prerequisites & 2.1.7.2 number & \\
\hline 1.3.1. prerequisite (id) * & 2.1.7.3 restrictions & \\
\hline 1.4. sections & 2.2 institution (id, type) * & \\
\hline 1.4.1 section (id, type) * & 2.2 .1 name & \\
\hline 1.4.1.1 location & $2.2 .2 \mathrm{url}$ & \\
\hline 1.4.1.2 day & 2.3 address (id, type) ${ }^{*}$ & \\
\hline \multirow[t]{2}{*}{ 1.4.1.3 time (begin, end) } & 2.4 working hours & \\
\hline & 2.4.1 item (id, day, time) * & \\
\hline Materials information & Calendar information & Policies information \\
\hline 4 materials_info & 5 calendar_info & 6 policies_info \\
\hline 4.1 offline & 5.1 activity (id, type, attendance)* & 6.1 policy (id, title)* \\
\hline 4.1.1 resource (id, type, lang, req, ref)* & 5.1 .1 title & \\
\hline 4.1.1.1 title & 5.1.2 place & \\
\hline 4.1.1.2 authors & 5.1 .3 date (begin, end) & \\
\hline 4.1.1.2.1 author (id)* & 5.1.4 time (begin, end) & \\
\hline 4.1.1.3 publisher & 5.1 .5 duration (type) & \\
\hline 4.1.1.4 y ear & 5.1 .6 outcome (id) ${ }^{*}$ & \\
\hline 4.2 online & 5.1.7 url & \\
\hline \multicolumn{3}{|l|}{ 4.2.1 resource (id, type, lang, req, url)* } \\
\hline \multicolumn{3}{|l|}{ 4.2.1.1 title } \\
\hline \multicolumn{3}{|l|}{ 4.2.1.2 authors } \\
\hline \multicolumn{3}{|l|}{ 4.2.1.2.1 author $(\mathrm{id})^{*}$} \\
\hline \multicolumn{3}{|l|}{ 4.2.1.3 publisher } \\
\hline \multicolumn{3}{|l|}{ 4.2.1.4 year } \\
\hline Support information & Additional information & Copyright information \\
\hline 7 support_info & 8 additional_info & 9 copyright_info \\
\hline 7.1 support (id, title)* & 8.1 additional $(\mathrm{id}$, title)* & 9.1 years (begin, end) \\
\hline
\end{tabular}

1) Elements given in parentheses are attributes, 2) Elements marked with a star $\left(^{*}\right)$ can be repeated many times as required

the activity elements with id, type and attendance attributes. Id is used for determining the order of activity; type shows the type or format of the activity such as lesson, laboratory work, exam etc. and finally attendance is used to show whether attending the event is compulsory or recommended. An activity element can have child elements which are title, place, date, time, duration, outcome and url. Title element has the name of the activity, in brief. Place is used to show the place of activity like classroom and/or lab labels. Date and time elements describe the beginning and due date and time of the activities, respectively. Duration is an optional element which can be used for showing the periodical works in days, hours and minutes. Outcomes are elements which give the results, experiences and/or knowledge gained from the activity and repeated as many times as desired. Finally, the URL element of each activity points to the Web or ftp address of activity online materials available on the Internet or intranets (Table 1).

Policy elements are identified with id and title attributes in a syllabus. Title attributes of policy element can contain one of the options such as attendance, grading, missed exams and tardiness. Order of the policies is defined with the id attribute (Table 1).

Supplementary information for academic honesty, disability, safety and health issues are described with support elements under support_info node element. Each support element is formed with id and title attributes that define the order and title of the information, respectively (Table 1).

The lack of extensibility was determined to be an important issue in the current versions of the online syllabus XML files reviewed on the Web. The extensibility for syllabus can be achieved with the use of 
an additional information section. This section can be used to explain some special notes like personal communication matters, holidays and/or unexpected situations which should be given to the students, if applicable.

Finally, copyright information includes the copyright years and institutions of the copyright owners. The copyright years are coded with begin and end attributes in years element and order, the name and web address of the institution are shown with the id, name and url attributes of the institution element, respectively (Table 1).

\section{FRAMEWORK AND WORKING MODEL}

Any tool managing course syllabi should, at least, offer components for building and editing the documents. At the same time, the tools should be easily installable and compatible with existing systems in widely used operating platforms.

In order to reach these goals, the tool SyllabuserXML developed in this study was based on the core technologies of XML, XSL, HTML and MS Active Server Pages (ASP) and it was tested on MS Internet Information Server as Web server. SyllabuserXML is a freeware and it is still under development. The tool can be accessed and downloaded under GNU license at http://cebeciz.cukurova.edu.tr/tools/syllabuserxm1. Therefore the source of SyllabuserXML tool might be recoded or modified for different purposes and/or platforms.

SyllabuserXML is distributed as a light software package that contains four main files (Table 2). In order to use the tool, all files in the distribution package should be extracted to a working directory on the Web server and open for instructors to make accessible online. For creating a certain course syllabus, as illustrated in Fig. 1, the following steps should be followed:

- Instructors access the syllabuser-ui.htm and fill in the form elements displayed in their browsers. All the functions in the client side is written in Javascript for browser compatibility.

- When the form is submitted to the server, the syllabus builder named syllabuser-build.asp which is a server side script runs automatically.

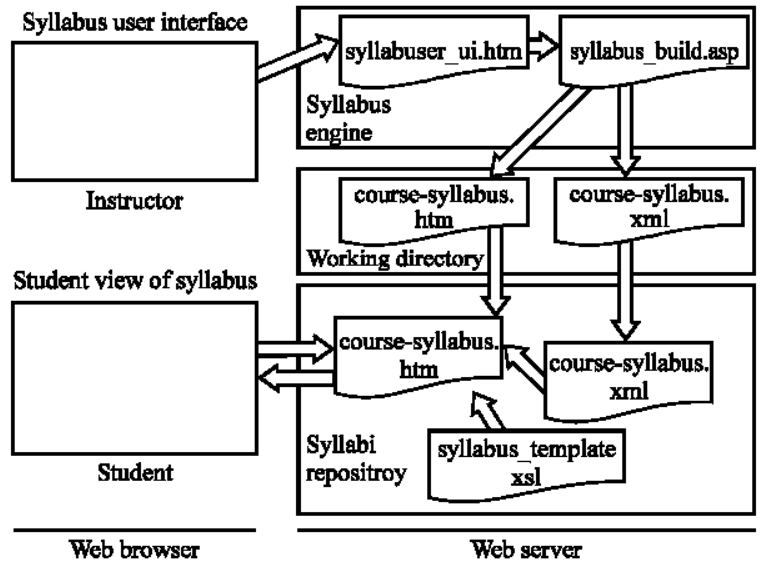

Fig. 1: Functional framework diagram of SyllabuserXML

- Syllabus builder creates two files named coursesyllabus.htm and course-syllabus.xml. Here, course stands for the course number previously entered on the form by the instructor. SyllabuserXML assumes that the syllabus files are identified with their course code. Course-syllabus.xml file contains all of the information in XML format. Course-syllabus.htm file contains only the codes to display the information stored in the relevant XML file.

- After the above mentioned syllabus files are created, they should be copied into a syllabus directory, a catalogue site and/or a syllabi repository.

- For displaying a course syllabus, its relevant htm file should be referenced in the users' browsers.

- When a request to a syllabus htm file is received by Web server it reads the information (elements) from the relevant XML file and displays the content according to the definitions coded in the syllabus display template file named syllabus_template.xsl and therefore it must be copied to the same directory with syllabus files in XML.

Young et al. ${ }^{[18]}$ remarks that if the course title or syllabus was not attractive at first sight, students might not double-click on the course for more information. Therefore, in the design of a syllabus tool, flexible viewing capability should be taken into consideration. Thus elements in the syllabus content can be displayed in different formats for different purposes. This flexibility can

Table 2: Components of syllabuser XML tool

\begin{tabular}{lll}
\hline Component & Function & Name and size of files \\
\hline Instructor interface & To enter the syllabus information & Syllabuser_ui.htm, 46K \\
Syllabus creator & Template to display user interface & Syllabuser_ui_css, 3K \\
View template & To form syllabus files for publishing via online media & Syllabuser_build.asp, 9K \\
Logo image & To customize the views of syllabus & Syllabuser_template.xsl, 16 \\
\hline
\end{tabular}



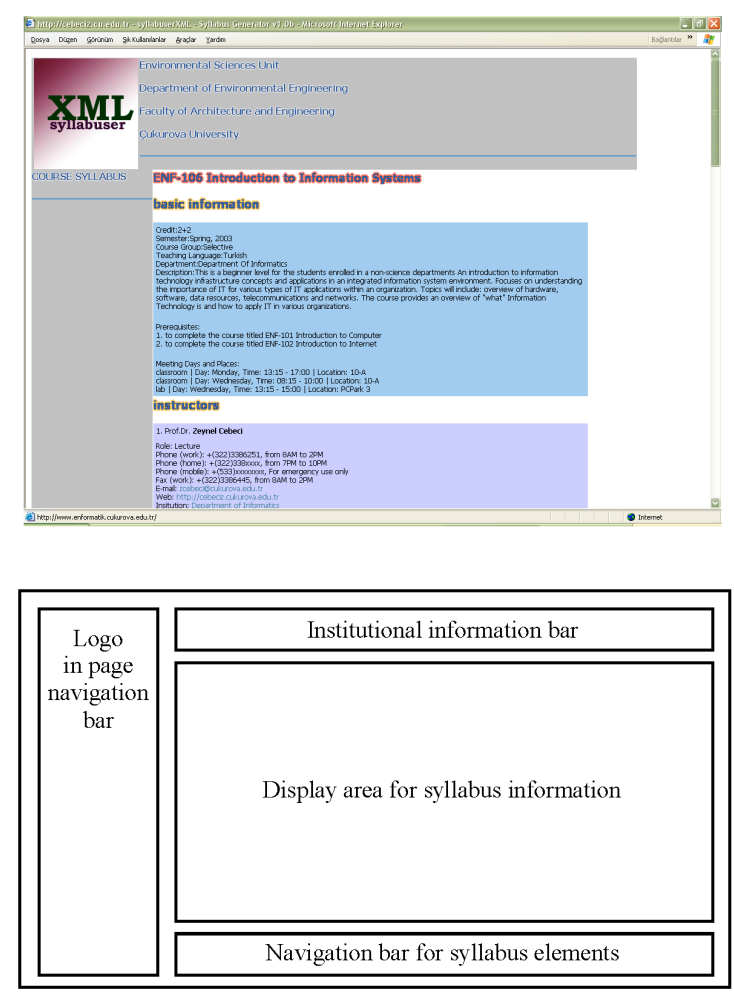

Fig. 2: Screenshot (top) and schematic view of a sample course syllabus

be reached with the use of different syllabus extensible Style Sheet Language (XSL) templates for desired display output in HTML. XSL template files can also be modified for producing other file formats like PDF and/or text output for printing and publishing.

In the predefined version of syllabus view there is provided a distribution package of SyllabuserXML tool and there are four main sections for each syllabus. In this type of viewing which is a common approach in Web page design the view area of a syllabus consists of four sections as shown in Fig. 2. A logo chosen by the users is shown at the top of a vertical column that aligns on the left side of display screen. Along this column there are anchors to navigate in the viewed page quickly.

At the top of the page on the right side, the name of the organization and their departments are displayed according to the order of hierarchy from sub units to super units as identified by id attributes of unit elements in XML file. This bar is followed by the information of a syllabus. At the end of the page, there is a horizontal row for quickly going to the information elements displayed in the information area.

Buuck et $a l .^{[13]}$ argued that colors on the online syllabus must have the appropriate contrast ratio. They also states that the placement of elements on the syllabus should enable the user to spot information quickly and transfer from one syllabus component to another with ease while minimizing the time of transition. In order to achieve this flexibility, different XSL files can be formed for getting the desired appearance and navigational model for the content of a syllabus. The master XSL template provided with the distribution package of the SyllabuserXML can be easily customized to the preferences of its users.

\section{CONCLUSIONS}

Creating and managing of course syllabi with online tools reduce the amount of physical work required in the distribution, editing and subsequent maintenance of the syllabi and therefore decrease the costs made by the institutions. Generally speaking, online syllabus tools will promote active learning and teaching. SyllabuserXML as an example of this sort of tool requires no advanced level of system knowledge, Web designing and programming experiences for easy management and further enhancements. The experiences gained with the SyllabuserXML showed that online services and tools for syllabi construction can contribute much to broad-sense understanding and usage of e-learning in classes by the teaching community.

Recently, the intensive studies have been carried out to utilize the advantages with XML and its related technologies in teaching and learning. IEEE LTSC works on the learning technology standards that aim to facilitate search, evaluation, acquisition and use of learning objects, for instance by learners, instructors or automated software processes. The commission completed a draft version of learning object metadata standard (IEEE 1484.12.1-2002) as the first part of a multipart standard in $2002^{[19]}$. The studies on XML binding and RDF binding of this standard are still under development. This standard known as IEEE LOM aims to define the elements and rules for building the metadata of learning objects.

Similar works on the standardization of course syllabus construction and its XML implementations are also needed as discussed above. In 2002, the syML, a syllabus markup language based on XML was a pioneering work done by Black from Seton Hall University ${ }^{[20]}$, however, the present application of syML can be considered somewhat difficult to include some of syllabus elements in an extensible way. Further studies on XML-based construction of course syllabi will contribute to produce interoperable, re-purposable and sharable syllabi among the parties. In the future it is expected that there will be a pressure for standardizing projects in the 
structure of online syllabi. The approaches and tools discussed in this study can be considered as an example of the studies that point to the advantages of XML in preparing syllabi with online systems. The integration of the open-source software like SyllabuserXML into existing or forthcoming LMS/LCMSs will minimize the costs and time required in the developmental phase of these kinds of projects.

\section{REFERENCES}

1. Hall, G., 1999. Redefining the syllabus: An investigation into wether syllabuses can meet learners' linguistic and social needs. CRILE Working Papers No. 45. http://www.ling.lancs.ac.uk/ groups/crile/docs/crile45hall.pdf, last accessed 15 January 2004.

2. Anonymous, 2004. Syllabus Tutorial. Center for Teaching and Learning Services, University of Minnesota, USA. http://wwwl.umn.edu/ohr/ teachlearn/syllabus/index.html, last accessed 15 January 2004.

3. Altman, B.H. and W.E. Cashin, 1992. Writing a syllabus. Idea Paper No. 27, Center for Faculty Evaluation and Development. Kansas State University.

4. Grunert, J., 1997. The Course Syllabus: A Learning Centered Approach. Anker Publishing Company, Inc. Bolton, MA., pp: 112.

5. Welsh, T., 2000. An evaluation of online syllabi in the university of tennessee college of communications.

ALN Magazine. 4(2) http://www.sloanc.org/publications/magazine/ $\mathrm{v} 4 \mathrm{n} 2 /$ welsh.asp, last accessed 10 January 2004.

6. Cohen, D., 2003. Syllabus Finder. Center for History and New Media, George Mason Univ., VA, USA. http://chnm.gmu.edu/tools/syllabi/, last accessed 15 January 2004.

7. AAR, 2004. The Syllabus Project by AAR Committee on teaching and learning, http://www.aarweb.org/ syllabus, last accessed 20 January 2004.

8. Google, 2004. http://www.google.com, last accessed 10 January 2004.

9. University of Utah-UOnline, 2004. Syllabusbuilder tool. http://services.tacc.utah.edu/ syllabusbuilder/CreateSyllabus.html, last accessed 16 January 2004.
10. Feather River College, 2004. Syllabus maker template. http:/www.frcc.cc.ca.us/home/geninfo/ syl.htm, last accessed 16 January 2004.

11. Kreis, J., 2002. Syllabus tool. Instructional Support Group, University of Arizona. http://moats.arizona.edu/syllabus/index.html, last accessed 16 January 2004.

12. StudentHub, 2004. Syllabus maker. http://www.studenthub.org/syllabus/start.php, last accessed 16 January 2004.

13. Buuck, A., N. Dishman, S. Hanrahan, J.Oser, M. Perry and P. Stults, 1998. Human factors standards for the design of online syllabi. Presented at the 28th Annual Conference of the Society for Computers in Psychology. http://psych.hanover.edu/research/ syllabus/syllabus.html, last access 6 August 2004.

14. Bray,T., J. Paoli, C.M. Sperberg-McQueen, E. Maler and F. Yergeau, 2004. Extensible Markup Language (XML) 1.0 (3rd Edn.,W3C Recommendation 04 February 2004, http://www.w3.org/TR/REC-xml, last accessed 27 June 2005.

15. Walsh, N., 1998. What is XML? http://www.xml.com/ pub/a/98/10/guide1.html, last accessed 12 January 2004.

16. Ditch, W., 2003. The Increasing Importance of XML in Education-and what you need to know about it. JSC Tech. and Std. Watch Rep. \#TSW 03-02. 25 pp. http://www.jisc.ac.uk/uploaded_documents/tsw_0302.doc, last accessed 27 July 2004.

17. Enerson, D.M., R.N. Johnson, S. Milner and K.M. Plank, 1997. The PenState Teacher II: Learning to Teach; Teaching to Learn. University Park, The Pennsylvania State University Press, PA., pp: 212. online handbook, available on request to http://www.psu.edu/celt/PST/feedback.html .

18. Young, S.S.C., T.W. Chan and C.B. Lin, 2002. A preliminary evaluation of a web-mediated 'School for All'. J. Comp. Ass. Learning, 18: 209-218.

19. IEEELTSC., 2002. IEEE 1484.12.1-2002: Standard for Learning Object Metadata. http://tsc.ieee.org/wg12/ files/LOM_1484_12_1_v1_Final_Draft.pdf, last accessed $1 \overline{2}$ February 2004 .

20. Black, D.A., 2002. SyML - The syllabus markup language. http://icarus.shu.edu/dblack/SyML, last accessed 16 January 2004. 